\title{
Distribution and status of the Pallas's Fish Eagle Haliaeetus leucoryphus in Mongolia: a cause for conservation concern?
}

\author{
MARTIN GILBERT, RUTH TINGAY, JAMBAL LOSOLMAA, NADIA SUREDA, \\ COLIN GILBERT, DAVAASUREN BATMUNKH and SUNDEV GOMBOBAATAR
}

\section{Summary}

Pallas's Fish Eagle Haliaeetus leucoryphus (PFE) is sparsely distributed across a vast swathe of central, eastern and southern Asia, and is classified as 'Vulnerable' by IUCN on the basis of population size and reports of declines in many areas. Mongolia has long been considered a breeding stronghold for the species, but evidence to support this is unclear. Our objective was to assess the current distribution and status of the PFE in Mongolia to enable a more accurate assessment of the species' conservation status, through collation of existing information from the historical literature, and a contemporary survey of historical sites and potential PFE breeding habitat. Thirty-four traceable locations were identified in the historical literature, of which breeding activity had been recorded in seven. Field surveys were conducted at a total of 77 sites throughout the study period (2005-2011) between April and October, including 21 of the historical PFE locations. PFE were observed at eight sites, all of which were historical PFEs locations, and no evidence of breeding activity was recorded. These findings suggest that Mongolia is not (and may never have been) a breeding stronghold for the PFE. The lack of eagles at 13 of 21 historical sites surveyed, coupled with a lack of sightings of birds at alternative locations is suggestive of a decline in site occupancy. Observations of juvenile eagles within one month of the spring thaw suggests that at least a proportion of Mongolian PFEs are breeding at southern latitudes, and future studies to establish these migratory linkages are warranted. These findings, coupled with evidence of declines in other parts of the PFE range indicate a need to re-evaluate the species' conservation status, and in particular to determine the number of mature PFEs present in suitable habitat in the Indian Subcontinent and Myanmar between November and March.

\section{Introduction}

Pallas's Fish Eagle Haliaeetus leucoryphus (hereafter PFE) is considered the northern hemisphere's most poorly-studied eagle (Katzner and Tingay 2010). As a species with an apparently complex and poorly understood migratory system (Bildstein 2006, Naoroji 2006), it has a widespread distribution that includes large areas of central, southern and eastern Asia, but populations are thought to be declining across substantial parts of its range (BirdLife International 2001, 2012a, Sourav et al. 2011, Gombobaatar et al. 2011). Classified as 'Vulnerable' on the IUCN Red List (BirdLife International 2012b), these declines are attributed to the widespread loss, degradation and disturbance of wetland habitat, loss of potential nesting habitat, pollution from agricultural and industrial chemicals and human persecution (BirdLife International 2001, 2012a).

According to BirdLife International (2001, 2007), the three main breeding populations of PFE were believed to be in China, Mongolia and the Indian subcontinent, although there were few 
quantitative data to support that assessment. With reported "significant" PFE population declines during the $20^{\text {th }}$ century in China, Pakistan, India, Nepal and Bangladesh, it had been suggested that Mongolia held the main PFE breeding population (BirdLife International 2007). Since then, more evidence has suggested the Mongolian PFE population may be smaller than previously estimated (Gilbert and Gombobaatar 2009). Our study aimed to expand this work by collating existing data on historical and contemporary records of PFE in Mongolia, and to conduct field surveys at as many of these sites as possible, to assess the species' current distribution, identify key site characteristics and determine current status in the country. Our study provides the most up-to-date information currently available, based on an extensive review of published historical literature and the results of field surveys undertaken between 2005 and 2011.

\section{Study area}

Lying between latitudes $42^{\circ} \mathrm{N}$ and $51^{\circ} \mathrm{N}$, Mongolia is a vast land-locked country extending eastwest across 2,500 km of Central Asia between Russia and China, with an approximate area of 1.5 million $\mathrm{km}^{2}$. Although a country of climatic and geographic extremes (Wingard and Zahler 2006), much of the land area consists of open steppe, transitioning to taiga forest in the north and the Gobi Desert in the south and west. Wetlands and lakes of variable size fleck the landscape, with approximately 3,000 rivers stretching over $67,000 \mathrm{~km}$ in the north (Wingard and Zahler 2006). Mongolia is populated by just under 3 million people, over half of whom depend directly or indirectly on the traditional nomadic system of livestock production, raising goats, sheep, cattle, yaks and horses (Zahler et al. 2007).

\section{Methods}

\section{Historical literature review}

Forty-three Mongolian, Russian, German and English language sources (covering the period 1901-2009) were reviewed from the collections held at the National University of Mongolia and the Mongolian National Library, Ulaanbaatar. Sources were reviewed to identify information relating to historical PFE distribution and status. Localities were mapped using 1:500,000 topographical maps and a national road atlas $(1: 2,000,000)$. Imprecise localities such as long river corridors were classified as 'general areas', whereas place names or defined geographical features such as lakes were classified as 'specific locations'. Where sources referred to museum specimens, we endeavoured to verify the records by consulting with the museum collection curators.

\section{Field surveys}

These were conducted each year (2005-2011) between April and October, encompassing the period during which PFEs have been recorded in the historical literature. The surveys were a combination of both opportunistic and targeted site visits. The opportunistic surveys ran concurrently with an avian influenza surveillance programme focusing on wetlands throughout Mongolia, covering 12 of the 21 national aimags or provinces (Gilbert et al. 2012). During these surveys, sites were selected either on the basis of locations cited within the historical literature review (the PFE-targeted survey), or by the presence of congregatory waterbirds (particularly Anseriformes and Charadriiformes) (opportunistic surveys), and included rivers and lakes of variable size. Surveys were conducted using a combination of transport including motor vehicle, on foot and an inflatable zodiac boat with $25 \mathrm{hp}$ outboard motor, traveling parallel to the shore as close as water depth, vegetation or terrain allowed. A hand-held GPS (Garmin) was used to record the distance travelled at each site. Regular stops were made to scan for perched or flying eagles using binoculars ( $8 \mathrm{x}$ 32) and spotting scopes ( $80 \mathrm{~mm}, 20-60 \mathrm{x}$ zoom). The coordinates of all sighted PFEs were recorded and age was estimated, based on plumage characteristics (Naoroji 2006). Age was classified 
as adult (full adult plumage attained in $4^{\text {th }}$ or $5^{\text {th }}$ year), sub-adult (had at least initiated one moult cycle, but not yet attained full adult plumage) and juvenile ( $<1$ year). We also recorded the presence of White-tailed Eagles Haliaeetus albicilla, the only Haliaeetus congener in Mongolia that shares a cosmopolitan diet with the PFE (Naoroji 2006) and is a potential competitor for breeding sites. We also recorded the presence/absence of Great Cormorants Phalacrocorax carbo, an obligate piscivore and thus a crude indicator of fish stocks at each site.

\section{Wetland characteristics}

We categorised wetlands as either lakes or rivers. Lake surface area was measured using a GIS database (ArcGIS). Lake elevation was measured using a handheld GPS (Garmin).

\section{Results}

\section{Historical literature review}

PFEs were mentioned in 30 of the 43 reviewed literature sources, relating to 82 discrete observations from a total of 39 sites (Figure I). We elected to exclude a museum specimen held at the Museum of Zoology, Polish Academy of Sciences (catalogue number MIZ 41050, collected by B. Dybowski, and W. Godlewski on 9 August 1873), as we were unable to confirm that the collection locale (listed as "Dauria") lay within the territory of modern-day Mongolia. Twenty sites were classified as specific locations, I4 as general areas and five were untraceable (of which Kharaa Gol [river] could be traced to Khentii aimag [province], but the actual location of the river could not be determined). Although presence of PFE was used among the justifications for listing the Darkhad Valley as an Important Bird Area (BirdLife International 2004), we were unable to locate any specific records of the species in this location, nor were local people familiar with the species and so we did not consider this locality among our list of historical sites. Of the 40 observations where the number of eagles was specified, only three reported more than two birds present: five birds of

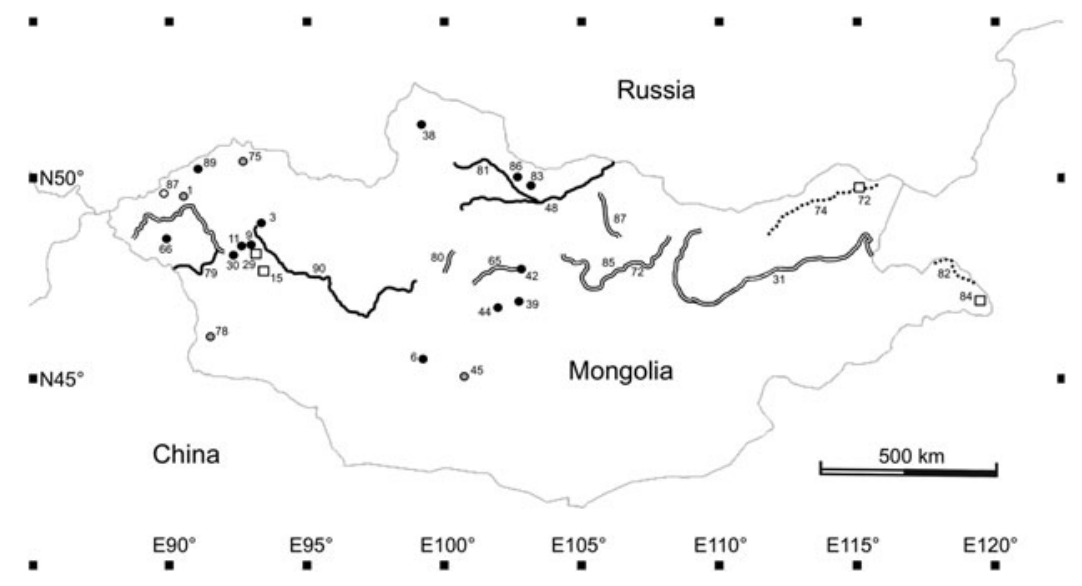

Figure 1. A map illustrating 34 locations where Pallas's Fish Eagle has been reported in Mongolia based on literature sources. Observations are illustrated within time periods consistent with the scheme used in BirdLife International (2001), and classified as 'specific locations' (white squares $=$ undated, white circles $=$ pre-1950, grey circles $=1950-1979$, black circles $=1980$ to present), or 'general areas' (dashed line = undated, white line = pre-1950, grey line $=1950-1979$, black line $=1980$ to present). The key to location numbers is presented in Table $\mathrm{S}_{1}$. Four locations could not be traced and therefore are not illustrated. 
unspecified age at Uureg Nuur on 24 May 1977 (Baranov 1991); seven birds of unspecified age at Buuntsagaan Nuur in June 2003 (Bold 2005); six adults and 15 immatures at Airag Nuur in June 1995 (A. Bräunlich in Birdlife International 2001). Within the 30 references where PFEs were mentioned, only five referred to breeding PFEs at seven sites (Table $\mathrm{S}_{\boldsymbol{I}}$ in the online supplementary materials). One of the five references (Fisher 1970 in Stubbe et al. 2010) makes a generic reference to PFE as "breeding visitors" in two specific locations (Buuntsagaan Nuur and Orog Nuur), but it is unclear whether definitive evidence of nesting activity was observed, or birds were merely present during the perceived breeding period. Three references (Buturlin 1913 in Sumiya and Skryabin 1989, Tugarinov 1928 in Stubbe et al. 2010, Kozlova 1930) mention an unquantified number of nests in three general areas (Tuul Gol at Urguu [Ulaanbaatar], Tamir Gol and Kherlen $\mathrm{Gol}$ ) and one specific location (Khuvsgul Nuur). Only one reference (Sh. Boldbaatar in Stubbe et al. 2010) quantified breeding attempts at a specific location with a single nest containing a single egg on 24 June 1999 (at Tsagaan Gol, Khar-Us Nuur). We attempted to determine where the egg is currently held, but we understand it was not collected (Boldbaatar pers. comm.). Although BirdLife International (2001) cite Sushkin (1938) as a source for information on PFE nesting on the ground in Mongolia, we were unable to find reference to this in the primary text.

The process of collating historical records was complicated by the distribution of information in source material in several different languages. For instance, we found that observations of PFE reported along the Kherlen Gol and Churchin Gol by Popov (1991) in Stubbe et al. (2010), actually referred to White-tailed Eagles, and were likely to have been due to a mistranslation from the original Russian text.

\section{Field surveys}

A total of 77 sites were visited including 21 of the 34 traceable, historical PFE sites (Table S2 and Figure 2), and all seven of the locations with historical reports of breeding activity. The number of individual site visits totalled 234 and ranged from one to 24 visits per site (mean number of visits $=3.0$, SD 3.6). Fifty-seven of the 77 sites received full survey coverage at least once, and 20 sites received partial survey coverage due to accessibility or other logistical difficulties. PFEs were observed at eight sites (Table I), all of which were known historical sites. The number of individual PFEs observed at any site ranged from one to six. The number of PFEs in each age

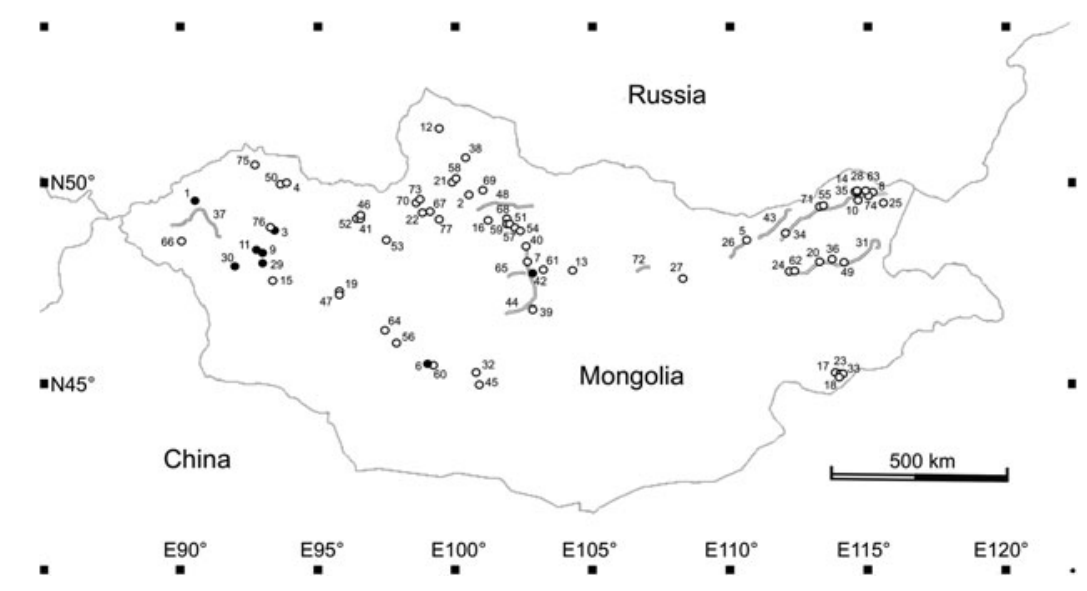

Figure 2. A map illustrating locations in Mongolia where surveys took place for Pallas's Fish Eagle between 2005 and 2011. Survey sites include lakes or rivers of limited length (white circle = no eagles observed, black circle $=$ eagles observed), and longer rivers ( white lines $=$ no eagles observed). The key to location numbers is presented in Table $\mathrm{S}_{2}$. 
Table 1. Observations of Pallas's Fish Eagles made during surveys between 2005 and 2011.

\begin{tabular}{llllll}
\hline Site name & Date surveyed & Distance surveyed & Adult & Subadult & Juvenile \\
\hline Buuntsagaan Nuur & 1-Aug-05 & 20.53 & - & - & I \\
Ugii Nuur & 27-Aug-06 & 10.07 & 1 & - & - \\
Ugii Nuur & 18-Aug-07 & 15.03 & 1 & - & - \\
Ugii Nuur & 22-Aug-07 & 15.03 & 3 & - & 2 \\
Ugii Nuur & 29-Jul-08 & 15.03 & 1 & 1 & - \\
Ugii Nuur & 16-Aug-08 & 23.33 & 1 & 1 & - \\
Ugii Nuur & 21-Jul-09 & 15.03 & 2 & - & 1 \\
Khar Us Nuur & 12-Aug-09 & 200.08 & 3 & - & - \\
Airag Nuur & 15-Aug-09 & 56 & 4 & - & 2 \\
Achit Nuur & 18-Aug-09 & 80.1 & 1 & 1 & 1 \\
Dalay Nuur & 21-Aug-09 & 14.7 & 1 & - & - \\
Chono Kharaikh Gol & 21-Aug-09 & 38.55 & - & - & 1 \\
Khar Nuur & 22-Aug-09 & 108.52 & - & 1 & - \\
Buuntsagaan Nuur & 25-Aug-09 & 85.5 & 1 & 1 & - \\
Ugii Nuur & 19-Jun-10 & 15.03 & 1 & - & 1 \\
Ugii Nuur & 29-Jun-10 & 15.03 & 1 & - & 1 \\
\hline
\end{tabular}

class was 21 adults, five sub-adults, and 1o juveniles. Great Cormorants were observed at 36 sites, and White-tailed Eagles at 21 sites. There was a significant association between sites where PFEs were observed and where Great Cormorants were present (chi-value $=7.586, \mathrm{df}=1, P=$ o.006). Whereas, White-tailed Eagles were only observed at four of the PFE sites, an association that was not significant (chi-value $=1.387, \mathrm{df}=1, P=0.239$ ).

\section{Wetland characteristics}

Of the 77 survey sites, 65 were characterised as lakes, II as rivers and one was a wetland complex including both rivers and lakes (Table S2). All observations of PFEs were made on lakes with the exception of a single individual recorded along Chono Kharaikh Gol [river], at elevations between $1,030 \mathrm{~m}$ and $1,988 \mathrm{~m}$. The surface area of lakes visited ranged from 0.03 to $3,350 \mathrm{~km}^{2}$, with PFEs only observed on relatively large water bodies ranging from 25 to $1,077 \mathrm{~km}^{2}$ (Table S2).

\section{Discussion}

Our study casts doubt on the assumption that Mongolia was, or is, a breeding stronghold for PFE. The extreme climatic conditions in Mongolia will likely restrict the PFE's potential breeding period to the months of April-October, so that hatching is synchronised with the thaw in midMay (as with White-tailed Eagle, the PFE's congener; pers. obs.). Within 29 published historical accounts referring to these months, only five specifically mentioned PFE breeding activity (presence of nests or an egg). Of the 27 traceable, historical locations where no evidence of breeding was recorded, it is conceivable that authors either failed to observe or neglected to record breeding activity. However, our own contemporary surveys at 15 of these locations made during the same months did not produce any evidence of PFE breeding. It is possible that breeding PFEs could have switched to new breeding locations in response to changing environmental conditions at some historical breeding sites; however, we failed to find any evidence of breeding at 55 widely dispersed wetlands that were not documented within the historical literature review, and represented potential alternative breeding sites.

Although many observations of PFE involved juvenile birds, this does not necessarily imply that these individuals hatched within Mongolia. On several occasions juvenile eagles were observed in fresh plumage (with little or no evidence of wear) as early as June (pers. obs. and M. Valkenburg and W. Faveyts in litt. 2010). Considering that Mongolian water bodies remain 
frozen until late April or early May, it is likely that these birds hatched in locations south of Mongolia, and may be individuals from the breeding population in the Indian subcontinent. For example, the PFE's breeding season in northern India has been defined as September to March, sometimes into April, with adults and juveniles leaving by the end of April/early May when they "disappear northwards over the Himalaya into Tibet and the high plateau lakes of Western Xizang Zizhiqu in Central Asia" (Naoroji 2006). Similarly, Sourav et al. (2011) documented PFEs arriving to breed in Bangladesh in late August and leaving (for an unknown destination) by the end of April/early May.

With the exception of a museum specimen collected at Khuvsgul Nuur on 24 December 1912 (by F. Schillinger, in Piechocki 1983), all historical observations of PFEs in Mongolia were made between April and September. However, a re-examination of the Khuvsgul Nuur specimen (\#NMW 42.010) has determined that this bird is in fact a White-tailed Eagle (A. Gamauf, Naturhistorisches Museum Wien, in litt. 2013), and a second putative PFE obtained by the same collector in October 1913 (\#NMW 42.011) was also re-identified as this species. Recent observations of PFE in Kazakhstan include records from February and March (Kovalenko 2009), suggesting that at least a portion of that population may be present throughout the year (although probably not numerically significant considering the scarcity of the species there). This does not appear to be the case in Mongolia, where PFEs migrate during the severe winter months. With only four dated records of PFEs in China between November and March (BirdLife International 2001), it seems likely that the Mongolian population winters in latitudes south of the Himalayas, but further work is required to establish the nature of this connectivity.

The misidentification of the specimens collected by F. Schillinger highlights a potential source of error when reviewing records of PFE in the literature that are unsupported by specimens or irrefutable evidence such as photographs. Juvenile and subadult birds could conceivably be confused with several sympatric species within the genus Aquila, or with the congener Whitetailed Eagle. Adult birds are more distinctive, but confusion with White-tailed Eagle or juvenile Golden Eagles Aquila chrysaetos remains possible. As an example, Popov (2002) examined records of breeding PFE along the eastern shores of Lake Baikal and concluded that these records were more likely to have been observations of nesting White-tailed Eagles, which were otherwise overlooked by the surveyors. A similar conclusion was reached by Zhatkanbaev (2011) in relation to breeding records of PFEs in the Ile River Delta, Kazakhstan. However, even when museum specimens are available they need to be treated with caution. For example, Rasmussen and Prŷs-Jones (2003) documented a variety of uncertainty issues when relying upon these sources, such as data-poor labels, careless labelling, label substitution, problems with transliteration, translation, interpretation and reading of labels, unreliability of local collectors, misidentification, intentional fraud etc. For this reason we would encourage further research on putative PFE museum specimens from across the species' range that should include physically examining the specimens as opposed to relying on museum catalogue data. This may result in putative PFE specimens being re-identified as White-tailed Eagle, as well as putative White-tailed Eagles being re-identified as PFE.

Our failure to detect PFEs at 13 of 21 historical sites may be indicative of a decline in site occupancy of PFEs in our study area. However, it should be noted that our surveys were not comprehensive, as we were unable to visit a further 18 historical locations. It is also conceivable that we may have missed PFEs at large sites that were only partially surveyed. For example, Popov and Tupitsyn (2008) recorded the continuing presence of PFEs in the northern part of Khuvsgul Nuur that we did not visit. To address this limitation, we contacted ornithological tour groups to request details of their observations and we also reviewed contemporary bird sightings available on the internet (Table $S_{3}$ ). However, although we received responses from four tour group leaders and found seven internet sources reporting PFEs sightings, we were only able to find evidence of PFE at one further location (a single bird reported at Tolbo Nuur [site number 65, Figure 2] in May 2010, a site at which we had failed to detect PFEs). Although this is far from conclusive, we contend that our results are suggestive of a decline in site occupancy and recommend that future Mongolian surveys focus on the historical sites that we did not visit (Table $\mathrm{S}_{I}$ ). We further 
recommend that measures are taken to centralise PFE observations made by ornithological tour groups and other visiting birdwatchers in order to capture and collate potentially valuable data.

The lack of evidence of a large breeding population in Mongolia is of concern. Although we may have missed evidence of breeding at the historical sites that we were unable to visit, even if those 18 sites are currently occupied by breeding PFEs this would still not amount to a breeding stronghold. This has ramifications for the species' conservation status.

The conservation status of PFE was first classified as 'Vulnerable' in 1994, and it remains in this category to date (BirdLife International 2012b). However, in recent years declines have been reported in parts of the species' range including Russia (Vazhov et al. 2011), Kazakhstan (Berezovikov and Samusev 2003), Bangladesh (Sourav et al. 2011) and India and China (BirdLife International 2012a). These declines, coupled with the results of our study, suggest that this classification may no longer be an accurate reflection of the species' conservation status.

According to the current IUCN Red List, the C2a(ii) criterion used to assess the species' status can be split into three main parts: (C) Population size estimated to number fewer than 10,000 mature individuals, (2) A continuing decline, observed, projected or inferred, in the number of mature individuals, and (a[ii]) All mature individuals in one subpopulation (IUCN 2001). We agree that the population size is unlikely to exceed 10,000 mature individuals, but importantly we would suggest that this threshold (which triggers the status of 'Vulnerable') is probably a considerable overestimate and should now be reviewed, especially given the lack of both historical and contemporary evidence of a large breeding population in Mongolia. The next numerical threshold used by IUCN to trigger a status of 'Endangered' is a population size estimated to number fewer than 2,500 mature individuals; we suggest this figure is probably a more realistic estimate of the PFE's current population size. We also agree with part (2), that there is likely a continuing decline, observed, projected or inferred, in the number of mature individuals. This is plausible given the multiple sources citing declines in large parts of the species' range. The available evidence used to support part (a[ii]), that all mature individuals are considered to be in a single subpopulation, is less clear. With the possible exception of a relict population in Kazakhstan, it appears that all remaining northern populations migrate to southern latitudes during the northern winter. This has important implications for the interpretation of population data, as there is a risk of double counting for migratory birds that are observed at both limits of their annual movement cycle. With a population decline evident in several areas, the key element of criterion $\mathrm{C}$ that IUCN uses to differentiate between 'Vulnerable' and 'Endangered' status is the estimated population size of mature adults. We propose that an assessment of global population size is now a priority, and should take place in the southern portion of the species' range, between the months of November and March. Connectivity between populations also requires closer scrutiny, including research into the migratory movements of birds in the southern and northern parts of the range.

Assuming that there is a migratory connectivity between the Mongolian and southern PFE populations, then it follows that threats specifically affecting the species in Mongolia could have wider implications across the species' range. Potential threats previously documented for PFE in Mongolia include hydroelectric development, over-fishing and climate change (Gilbert and Gombobatar 2009). The recent construction of hydroelectric dams on the Chono Kharaikh Gol and Zavkhan Gol has disrupted water flow at several historical and contemporary PFE sites (including sites 9, II and 30 along the watershed of the dam at Chono Kharaikh Gol, and sites 3, 76 , and 9o, downstream from the Zavkhan Gol dam, Figures 1 and 2). There is also the potential threat of mercury poisoning from hydroelectric developments, particularly for piscivorous top predators (e.g. Elliott et al. 2000, Weech et al. 2006). The reliance of PFE on areas with significant fish stocks (estimated based on the presence of Great Cormorants) may indicate sensitivity to unsustainable harvesting of this resource. Illegal fisheries were in evidence throughout the survey period at Ugii Nuur (site number 42, Figures I and 2), a location that should be considered one of the most important PFE sites in Mongolia, and ice fishing was widely reported by nomadic herders in the western lakes (e.g. site number 29, Figure 2). Mongolia has also been experiencing a protracted decline in available surface water, leading to a reduction in water levels at many lakes, 
and drying of several river drainages of importance to PFE (for example site numbers 6, 45, 72 and 74 , Figures 1 and 2) (Sternberg 2008, Sukh 2012). Long-term climate models predict that this trend is likely to continue, and could lead to further loss of PFE habitat in the coming years (Simonov and Dahmer 2008).

\section{Conclusions}

We conclude that Mongolia is not a breeding stronghold for PFE and probably never was, as we could find no material evidence suggestive of breeding activity in either the historical record or during our own extensive field surveys. The population that is there is small and there is evidence of a decline in site occupancy. There is an urgent requirement to undertake satellite telemetry studies to determine the migratory linkages between Mongolia and areas in the species' southern range. To properly evaluate the conservation status of the species there is an urgent need to collate contemporary data on the population of PFE (particularly mature individuals) in the southern portion of the range including the Indian subcontinent, and potentially to include surveys in under-studied areas such as Myanmar. The completion of these studies would be essential to facilitate a reassessment of the species' conservation status, which may be more endangered than currently recognised.

\section{Supplementary Material}

The supplementary materials for this article can be found at journals.cambridge.org/bci

\section{Acknowledgements}

We sincerely appreciate the support of The Peregrine Fund for providing funding for the 2009 PFEtargeted field surveys. We extend our gratitude to David McAdams for contributing sightings and assisting in field surveys, also to Machiel Valkenburg and Wouter Faveyts (Central Asia Birding), Mark Beaman (Birdquest), James Lidster (Sunbird), Kiera Griffin (Naturetrek), Rebecca Waters and Dick Forsman for comments on Pallas's Fish Eagle sightings. We are also grateful to Markus Jais and Mayke Leggewie for help with German translation, and Jevgeni Shergalin, Igor Fefelov and Victor Popov for assistance with Russian literature sources. Finally, we would like to thank Anita Gamauf for researching putative PFE specimens archived at the Naturhistorisches Museum Wien, Vienna, and to Thomas Trombone at the American Museum of Natural History, and Mark Adams at the Natural History Museum, UK for their help in sourcing museum specimens.

\section{References}

Baranov, A. A. (1991) Rare and little-known birds of Tuva. Krasnoyarsk, Russia: Krasnoyarsk Publishing House KGU.

Berezovikov, N. N. and Samusev, I. F. (2003) Birds of Zaisan Valley. III. Falconiformes, Galliformes, Gruiformes. Russ. Ornithol. J. 12: $287-312$.

Bildstein, K. L. (2006) Migrating raptors of the world: their ecology and conservation. New York, USA: Cornell University Press.

BirdLife International (2001) Threatened birds of Asia: the BirdLife International Red Data Book. Cambridge, UK: BirdLife International.

BirdLife International (2004) Important Birds Areas in Asia: key sites for conservation. Cambridge, UK: BirdLife International.

BirdLife International (2007) Species factsheet: Haliaeetus leucoryphus. Available at: http://www.birdlife.org. Accessed on: 21 September 2008.

BirdLife International (2012a) Species factsheet: Haliaeetus leucoryphus. Available at: http://www.birdlife.org. Accessed on: 2 November 2012.

BirdLife International (2012b) Haliaeetus leucoryphus. In IUCN 2013. IUCN Red 
List of threatened species. Version 2013.1 Available at: http://www.iucnredlist.org. Accessed on: 20 January 2013.

Bold, A. (2005) The birds of the Buuntsagaan lake. Pp. $23^{-32}$ in A. Bold, Sh. Boldbaatar and Kh. Munkhbayer, eds. Birds, amphibians, and reptiles of Mongolia 2. Ulaanbaatar: Mongolian Ornithological Foundation. (In Mongolian).

Buturlin, S. A. (1913). Birds of Huvsgul expedition by S. V. Elpatevskii. in K. S. Elpatevskii, ed. Notes of Zoological Branch of the Imperial Society: Nature, anthropology, and ethnography. New Edition 1. Moscow. (In Russian).

Elliott, J. E., Machmer, M. M., Wilson, L. K. and Henny, C. J. (200o) Contaminants in Ospreys from the Pacific Northwest: II. Organochlorine pesticides, polychlorinated biphenyls, and mercury, 1991-1997. Arch. Environ. Contam. Toxicol. 38: 93-106.

Fisher, W. (1970) Ornithologische Beobachtungen und der Versuch einer Bestandserfassung der Vögel an den mongolischen Wüstenseen Orog-nuur und Buncagan-nur. Zool. Abh. Tierkd. Mus. Dresden 30: 101-129.

Gilbert, M. and Gombobaatar, S. (2009) The status and distribution of Pallas's Fish Eagle in Mongolia: a report on field surveys June-August 2009. Boise, Idaho: The Peregrine Fund.

Gilbert, M., Jambal, L., Karesh, W. B., Fine, A., Shiilegdamba, E. et al. (2012) Highly pathogenic avian influenza virus among wild birds in Mongolia. PLoS ONE 7(9): e44097. doi:10.1371/journal.pone.0044097.

Gombobaatar, S. and Monks, E. M. (compilers), Seidler, R., Sumiya, D., Tseveenmyadag, N., Bayarkhuu, S., Baillie, J. E. M., Boldbaatar, Sh., Uuganbayar, Ch. (editors) (2011) Regional Red List Series Vol. 7. Birds. London and Ulaanbaatar: Zoological Society of London, National University of Mongolia and Mongolian Ornithological Society.

IUCN (2001) IUCN Red List Categories and Criteria: Version 3.1. Gland, Switzerland and Cambridge, UK: IUCN Species Survival Commission.

Katzner, T. E. and Tingay, R. E. (2010) Eagle diversity, ecology and conservation. Pp. I-25 in R. E. Tingay and T. E. Katzner, eds. The eagle watchers. New York, USA: Cornell University Press.
Kovalenko, A. V. (2009) Modern records of the Pallas' Fish Eagle in Kazakhstan. Raptors Conserv. 15: 134-139.

Kozlova, E. V. (1930) Birds of southwest Zabaikal, North Mongolia and Central Gobi. Leningrad: Academy of Sciences USSR. (In Russian).

Naoroji, R. (2006) Birds of prey of the Indian subcontinent. London, UK: Christopher Helm.

Piechocki, R. (1983) Abriß zur Erforschungsgeschichte der Avifaunamongolica. Erforsch. Biol. Ress. MVR, Halle (Saale) 3: 5-31.

Popov, V. V. (1991). Notes on the distribution of rare species of birds in Hentii province. In: Ecology and bird fauna in Eastern Siberia. Ulan-Ude. Pp. 147-151. (In Russian).

Popov, V. V. (2002) Pallas's fish eagle Haliaeetus leucoryphus in southern Siberia. Eng. Ornitol. Journal. Express-issue. 175(S): 124-130.

Popov, V. V. and Tupitsyn, I. I. (2008) About the distribution of birds of prey in Northern Hubsugul Lake Region, Mongolia. Raptors Conserv. 14: 116-117.

Rasmussen, P. C. and Prŷs-Jones, R. P. (2003). History os mystery: the reliability of museum specimen data. Bull. Brit. Ornithol. Club Supplement 123A: 66-94.

Simonov, E. A. and Dahmer, T. D., eds. (2008) Amur-Heilong river basin reader. Hong Kong: Ecosystems Ltd.

Sourav, S. H., Ahmed, B. and Thompson, P. (2011) Pallas's Fish Eagle Haliaeetus leucoryphus in Bangladesh. Birding ASIA 16: 101-105.

Sternberg, T. (2008) Environmental challenges in Mongolia's dryland pastoral landscape. J. Arid Environ. 72: 1294-1304.

Stubbe, A., Kaczensky, P., Wesche, K., Samjaa, R., Stubbe, M. and Reading, R. P. (2010) Exploration into the biological resources of Mongolia, Volume 11. Halle, Germany: Martin-Luther-Universität. (In German).

Sukh, T. (2012) Local understanding of hydro-climate changes in Mongolia. Fort Collins, USA: M.S. thesis, Watershed Science, Colorado State University.

Sumiya, D. and Skryabin, N. G. (1989) Birds of the Lake Hovsgol area, PRM [Ptitsy 
Prikhubsugulya, MNR]. Irkutsk, Russia: Irkutsk University Press. (In Russian).

Sushkin, P. P. (1938) Birds of the Soviet Altai and adjacent parts of north-western Mongolia. Moscow-Leningrad: Academy of Sciences of USSR Press. (In Russian).

Tugarinov, A. Ja. (1928) Neue Vogolformen aus der nördlichen Mongolei. Ezeg. Zool. Mus. 29: 267-270.

Vazhov, S. V., Karyakin, I. V., Nikolenko, E. G., Barashkova, A. N., Smelansky, I. E., and Tomilenko, A. A. (2011) Raptors of the Ukok Plateau, Russia. Raptors Conserv. 22: 153-175.

Weech, S. A., Scheuhammer, A. M. and Elliott, J. E. (2006) Mercury exposure and reproduction in fish-eating birds breeding in the Pinchi Lake region, British Colombia, Canada. Environ. Toxicol. Chem. 25: 1433-1440.
Wingard, J. R. and Zahler, P. (2006) Silent steppe: The illegal wildlife trade crisis in Mongolia. Washington DC: World Bank. Mongolia Discussion Papers, East Asia and Pacific Environment and Social Development Department.

Zahler, P, Joly, D. O., Krueger, L., Osofsky, S. A. and Enkhtuvshin, S. (2007) Poverty and biodiversity: improving poverty reduction and conservation outcomes in the grassland ecosystem of Mongolia. Pp. 89-96 in P. Steele, G. Oviedo and D. McCauley, eds. Poverty, health and ecosystems: Experience from Asia. Gland, Switzerland: IUCN and Asian Development Bank.

Zhatkanbaev, A. Zh. (2011) White-Tailed Eagle in the delta of the Ile River and on Balkhash Lake, south-eastern Kazakhstan. Raptor Res. 22: 76-91.

\section{MARTIN GILBERT* \\ Wildlife Conservation Society, 2300 Southern Boulevard, Bronx, NY 10460, United States.}

RUTH TINGAY, JAMBAL LOSOLMAA, NADIA SUREDA, COLIN GILBERT

Wildlife Conservation Society, P.O. Box 485, Ulaanbaatar 211238, Mongolia.

\section{DAVAASUREN BATMUNKH}

Mongolian Ornithological Society, P.O.Box 537, Ulaanbaatar 210646A. Mongolia.

\section{SUNDEV GOMBOBAATAR}

National University of Mongolia and Mongolian Ornithological Society, P.O.Box 537, Ulaanbaatar 210646A. Mongolia.

*Author for correspondence; email: mgilbert@wcs.org 